\title{
OPINION | Here are 12 steps to follow to bring about change in Tripura
}

\section{TRENDING}

TUE,20 JUL 2021

Meghalaya's health teams trek treacherous terrain fo..

SAT,17 JUL 2021

U Tirot Sing Syiem's last days - Captured or...

SAT,10 JUL 2021

Meghalaya's religious leaders to play key role in...

SUN,4 JUL 2021

Intersectionality as an approach in addressing...

\section{FEATURED}

TUE,20 JUL 2021

Meghalaya's health teams trek treacherous terrain fo...

TUE,20 JUL 2021

Morning News Nuggets

MON,19 JUL 2021

Meghalaya: Congress MLA \& MDC urge $\mathrm{CM}$ for...

MON,19 JUL 2021

Meghalaya: IIM Shillong holds Virtual Workshop fo... 
factors perpetuating low levels of private enterprise and efficiency of

governance services are rarely deliberated. Here are some of these issues, which if properly addressed, will bring about a change, much to the appreciation of the people of the state. These steps are also necessary for the new Government to fully implement its "Vision Document".

1. Fairness in recruitment, posting and transfer: Realizing this to be a major issue, the State BJP president and new CM, Biplab Kumar Deb had promised fairness in recruitment during his election campaign. The Vision Document promises "a transparent policy in recruitment, promotion and transfers". This needs to be implemented at the earliest and supplemented by fixed tenures, and a posting and transfer policy. Employees will then be able to concentrate on their assigned tasks, and be objectively assessed and rewarded for their performance. Talent will then be attracted and retained in Government service in the State. Only with such a professional work force, will the ruling party be able to deliver on its other promises.

2. Health services: For a State where $93 \%$ of health care is provided by Government hospitals, a high out-of-pocket expenditure - Rs 5581 on delivery and Rs. 5394 for other hospitalization in rural areas (NSSO, $71^{\text {st }}$ round, 2014) indicates prevalence of informal payments and non-availability of medicines. The State allows private practice, even by doctors in teaching positions at Government medical college. The conflict of interest between hospital based and private patient care affects quality of care in Government hospitals. Despite demands, rates of Non-Practicing Allowance remain low. These rates should be revised, and private practice banned for medical college faculty. Health personnel should be made responsible for quality of care and outcomes in Government hospitals.

3. Education quality: High literacy in the State mask the quality of teachinglearning. Private tuition by teachers are the accepted norm. As per NSS $\left(71^{\text {st }}\right.$ round, 2014), school students attending private coaching classes in Tripura, which stands at $76+\%$, was over two and a half times the national average. Private coaching by school teachers create a conflict of interest between class room teaching and home based tuition. It's not a surprise that the ASER survey, 2016 ranks quality of learning by children in class-VIII in the State to be lower than the national average. High dropout rate of $24 \%$ at secondary level could be partly due to quality of education. There are little easy options like limiting private tuitions and rigorous monitoring of class 
room teaching which can resolve the conflict of interest between class room teaching and home based tuition. The future of next generation is more important than the support of a few distraught teachers.

4. Activate Public Sector Enterprises: Most Public Sector Enterprises in the State - in the areas of Transport, Power, Horticulture, Tourism, Jute, Tea and Industry have been running in losses; their losses have increased many times in the last ten years. The loss to the State is much more than a simple drain on the budget - with little private investment and core infrastructure sectors, which could stimulate economic activity, are in a limbo. A vibrant Public Sector can spur economy by creating infrastructure for public transport, tourism, agriculture and horticulture processing and marketing, handloom and handicrafts, jute processing, tea production and processing, Information Technology enterprises, rubber processing and exports. For this, their heads ought to be professionals, rather than political appointees, made accountable through Memorandum of Understanding with the Government under the observer-ship of an oversight department, as is the practice in the Central Government.

5. Promote production and services: Despite impressive performance across sectors, the State remains a consumer in almost all sectors starting with foodgrains, household goods, basic items of mass consumption as rice, eggs and fish. Though trade with Bangladesh has increased six times to 305 cr. in last ten years, exports from Tripura are a tiny $1.5 \%$ of imports. In terms of relative sectoral contribution to State Domestic Product since 1999, manufacture (Secondary sector) has remained flat at around $13 \%$, while services (tertiary sector) has fallen from 55 to $51 \%$ despite expansion in government employment; the increased contribution of primary sector from $31 \%$ to $35 \%$ is largely because of mining of gas by ONGC, and partly due to expansion in fisheries and forestry sectors. Production of goods and services has to be promoted to generate employment avenues and increase incomes. Rubber, tea, fruits and vegetables processing, Tourism, biotechnology, IT and IT Enabled services, food processing, plant based medicines are areas in which new enterprises can productively thrive. Abundant natural gas and surplus power in the State can meet the energy needs for a resurgent industry. 
6. Promote residential schools for the children from poor, especially Tribal families: Education is the bridge for social mobility. Given the high dropout rates, especially among tribals at post-primary levels, the only hope for lifting generations out of poverty and shifting cultivation is to provide good quality education. Children from poor families can be sponsored for education in residential schools and their quality of instruction improved.

7. Reang Internally displaced persons from Mizoram in North Tripura have been living in enclosed camps as refugees for a generation (over twenty years). Being Indian Citizens, they have the right to settle in any part of the country, and should be given the option and support to settle in Tripura, in addition to the existing one, to return to their original land in Mizoram.

8. Promoting a Vibrant Civil Society: A suspicion of the civil society has prevented their growth in the State, while in neighboring Bangladesh immense contribution has been made in the social and micro-finance sector by the NGOs. An atmosphere of partnership needs to be created and the potential of civil society for outreach of development needs to be exploited, Bangladeshi NGOs like BRAC with proven track record in the health, education and economic development can be invited to the State to replicate their success.

9. Build a State Resident Data Hub (SRDH) and use it for targeting benefits: People are the primary targets of government efforts. For for delivery of services in a fair, transparent manner to the deserving, a database of residents and their Socio-Economic Status is a fundamental requirement. Many states have built such a database with assistance from UIDAl; survey for the National Population Register has been completed in the State, which if approved by MHA can form the foundation of such a database. Since Aadhar details are already a part of this data, various details of residents can be linked from Socio-Economic and Caste Census (SECC) of 2011, after its due updation. The database needs to be kept live by including births and dropping deaths, which is again possible in real time if the system of births and deaths registration in the state is complete. Aadhar can be issued along with Birth certificate, as being done in many States, or in case of default, at the Anganwadi centre. Real time data on the place, age, gender and cause of death can also form the foundation of an effective public health system. 
10. Impartial Beneficiary Selection: Discretion in beneficiary selection, when bestowed on local public representatives rather than objectively verifiable criteria, often contributes to biases of inclusion and exclusion. As a result, those eligible and needy are left out, while ineligible persons are included for extraneous considerations. The new government is well advised to opt for objective method of beneficiary selection, for which it could rely on the SRDH proposed above. The role of Gram Sabhas' in bringing transparency in decisions and ensuring that the most deserving get benefits, need to be strengthened.

11. Raise Forest Cover: Two thirds of the State is hilly, and $74 \%$ is covered by forests. In recent years, there has been a decline in forest cover (State of Forest Report, 2017). Recent years have also witnessed increasing incidents of floods as well as water scarcity. Given the State's subtropical climate, natural plantation is easier and requires lower resources. Regeneration of natural forest in the hills is essential not only for restoring ecosystem, but also for State's economy.

12. Making Police and administration unbiased: Officers need to be trusted, and given the freedom to implement the policies laid down by the Government of the day. Routine functions need to be delegated, officers given a free hand while also closely monitoring the results. Impartiality and objectivity should be rewarded, rather than subservience to the party in power. More than setting up of newer institutions, the conduct of administration, and an objective system of reward and punishment can send the desired message to perform in an unbiased manner.

The essence of democracy is to give a participative, effective governance. The process of churning through elections can be used as an opportunity for introspection, and learning from others. For, those who cannot remember the past, are condemned to repeat it.

Daily Fever

धरना दे रहे किसानों पर ट्रक चढ़ाने के प्रयास का आरोप लगाया

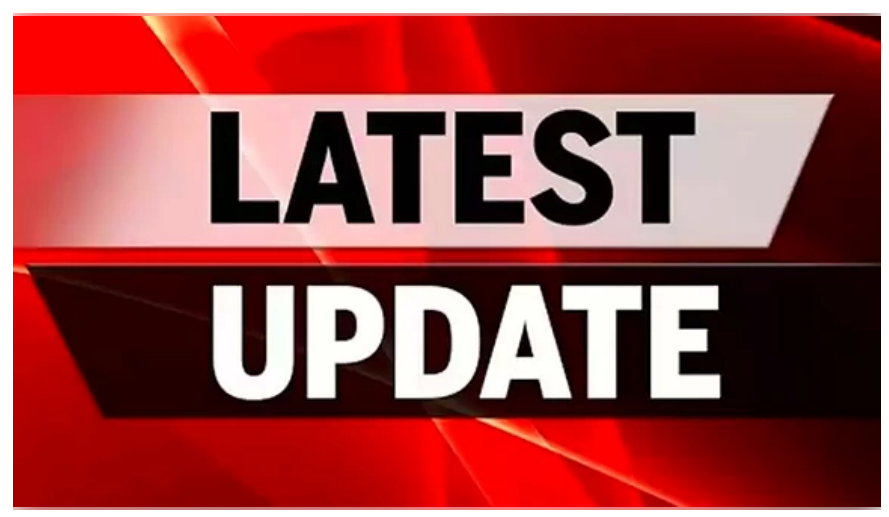


A progress on the above lines, over time, would certainly usher in all-round development and pave way for a prosperous Tripura. Only then will the change, for which people voted, will be fully realized.

(The writer is a civil servant. Views expressed in the article are personal and do not reflect those on any organization.)

Ad Squareyards

Rental home in your desired location within budget

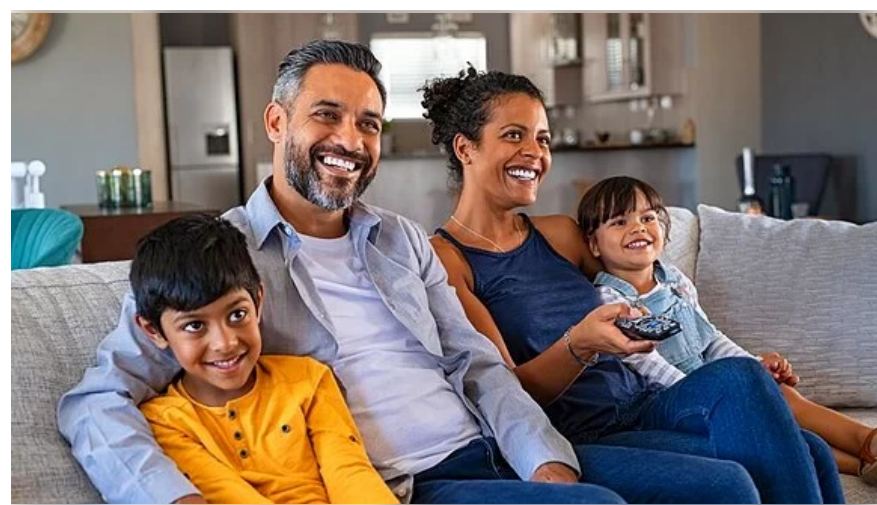

Recommended by Colombia

\section{SPONSORED CONTENT}

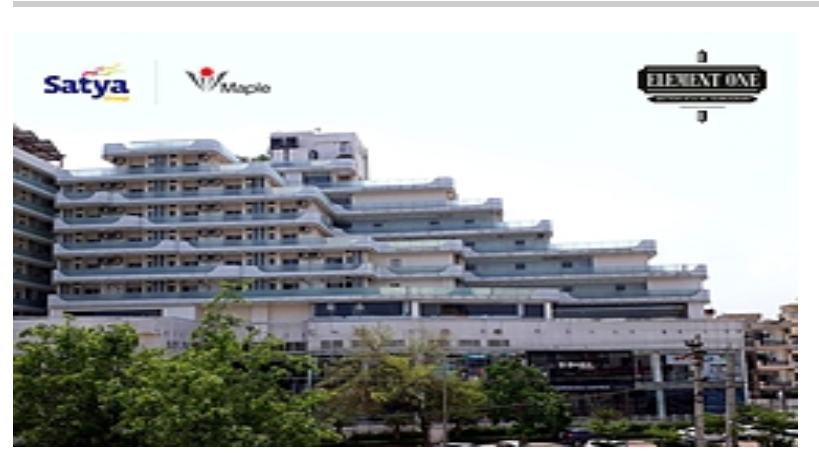

Top Chance to invest in Service Apartments in Gurgaon

Element One by Satya Group

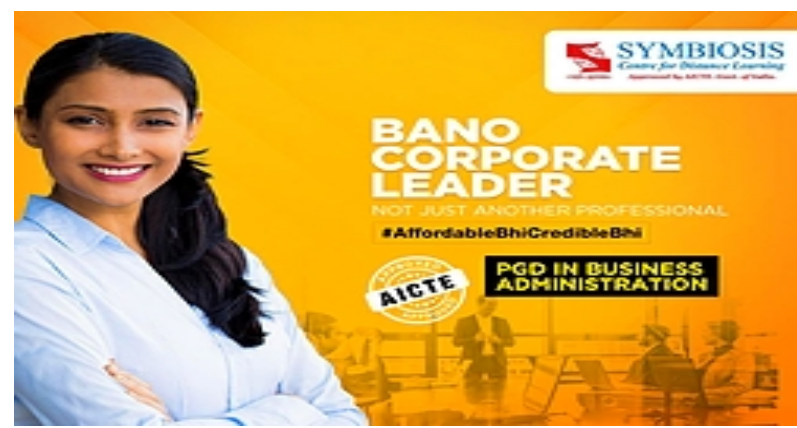

Few Seats Left! Apply for PGDM Programs @SCDL!

Symbiosis Online Programs

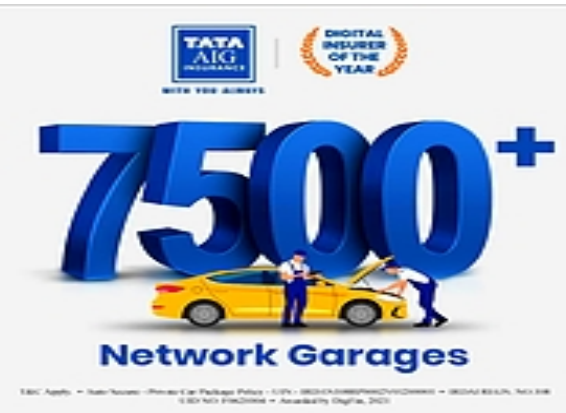

Secure your car with Tata AIG Car Insurance plan!

Tata AIG Car Insurance
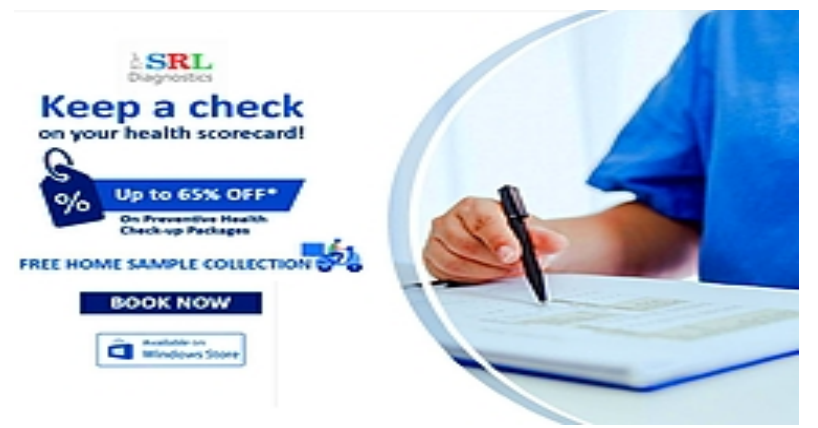

Home sample collection available SRL Diagnostics

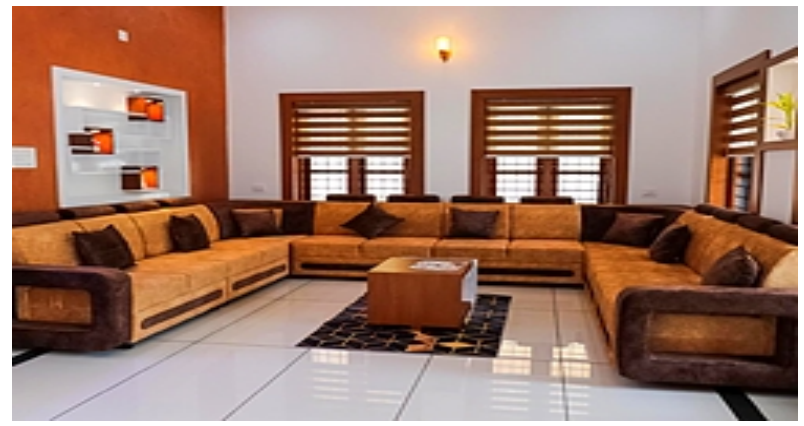

Say hello to your dream rental home! Squareyards

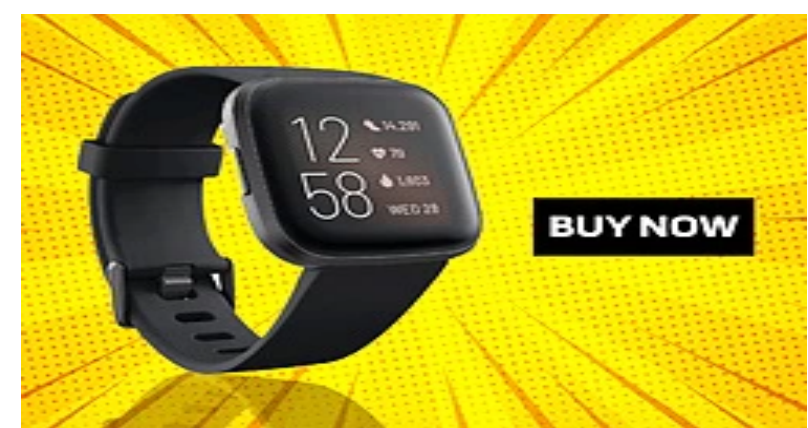

Fit Wise Watch - smart people's smartwatch! Fit Wise Watch 


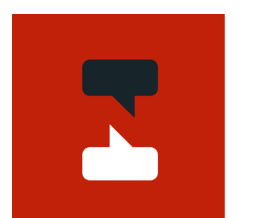

THE NORTHEAST TODAY
Thenortheasttoday.Com

Contact Us

About Us

Write to Us

\section{Follow Us}

Advertise with Us

(ㄷ) 2021 Thenortheasttoday.com, all rights reserved. 